customs, the law of the Porro, the savage ritual of the Bundu, and, dominating all, the ineradicable thraldom of the fetish. It is an interesting story of the making of empire among the savage races of West Africa which will well repay perusal, and the value of the work is much enhanced by the numerous capital photographs of scenery and native customs with which it is illustrated.

IV. T. P

\section{GEOLOGICAL NATURE-STUDY."}

THE sixth volume of "The Book of Nature Study" is devoted to what is styled "the Physical Environment." This, again, is subdivided into "Meteorology, \&c.," written by Dr. Marion I. Newbigin, and "Geology, \&c.," by Prof. IV. IV. WVatts. The titles of these subdivisions have been omitted, curiously enough, from the headings on pp. I and 92. Both authors, in pursuance of the plan of the work, guide the reader towards personal observation; and Dr. Nervbigin especially addresses herself to the teacher, and considers throughout how certain facts are to be brought home simply to a class. Prof. IVatts's pages are therefore more closely written and more enjoyable as literature, while those of his colleague are intentionally more didactic.

Throughout Dr. Newbigin's work there is a consistent attempt to impart just enough information to excite in. terest, and no more. The apostles of the centimetre scale will be shocked at the willingness of the author to accept

"slovenly" results. The teacher is invited to direct attention later to the difficulties that arise from careless measurement. In the case selected, however, that of the rain-gauge (p. 25), the errors would cause no difficulty at all; the results would simply be wrong at the end of a given time, and there would be no means of finding out the truth. This is just the sort of casy-going procedure that would suit the average child; but does it conduce to education? Is it not wiser to explain and illustrate methods of observation, but to refrain from records that cannot be accurate within reasonable limits? All

1 "The Book of Nature Study." Edited by Prof. J. Bretland Farmer, F.R.S. Vol. vi. Pp. viiit 244. (London: Caxton Publishing Co., n.d.) Price 8 s. $6 d$.

"Vorscbule der Geologie. Eine gemeinverstăndtiche Einführunz und Anleitung zu Beobachtungen in der Heimat." By Prof. I. Walther. Vierte Anleitung 24 Beobachtungen in der Hev Fischer, 19 ro.) Price 2.50 marks. Auflace. Pp. $x+294$. G Dr. H. Haas. Pp. viii 138. (Leipzig: Quelle v. Meyer, 19o9.) Frice Dr. H. Ha No. 2 I 22 , voL. $\left.8_{3}\right]$ explanations of natural phenomena have a partial character; we are always malsing suppositions in regard to an unknown. Dr. Newbigin, however, shows a real preference for the partial explanation, and we fear that the teacher would often have to go much further than is here indicated, when confronted with the child's persistent "Why?"

The passages on "floods," "drought and deserts," or "rainfall and vegetation," show how well the author writes and teaches, within the limits expressly imposed upon herself. Astronomical considerations, sunrise and sunset, time, summer and winter, involve more difficulty, and $\pi$ e cannot see our own way, in such instruction, to dispense with the good oldfashioned terrestrial globe-one, of course, without an elaborate setting, and preferably turning on a wire axis supported at one end only. Dr. Newbigin (p. 53) leaves this to a later stage and to the teacher of geography. Meanwhile, the child is instructed in

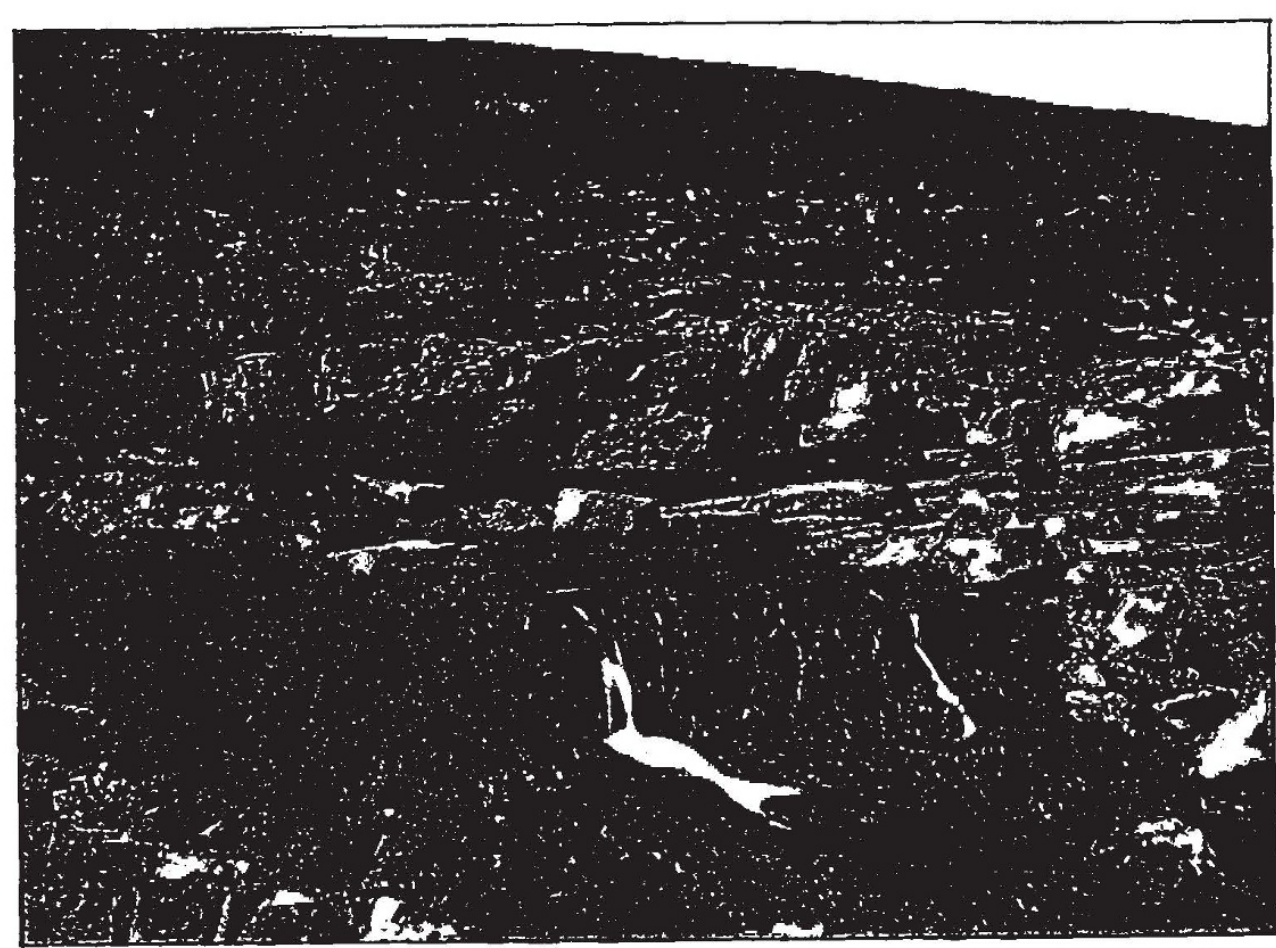

Spring issuing frcm Limestone. From "The E.ok of Nature Study."

nature-study scocentrically, and will surely soon find something to unlearn.

One point insisted on by the author, in common with many other writers, is that the atmosphere carries a "load of moisture." This phrase is, of course, singularly misleading when applied to invisible vapour, especially when the air is said to "throw down its burden" on cooling (p. 21 , for instance, where this is stated in three different ways). How is the child to realise that the air, when it has done this, becomes heavier than it was before? The matter was so well treated long ago in Sir A. Geilie's "Physical Geography" that it is wonderful how it is slurred over in ordinary teaching. Surely, again, the cold surface of a hill (pp. 20 and 22) has very little to do with the formation of cloud around it. "Vapour" is used in two senses on pp. I9 and $2 \mathrm{I}$, where invisible vapour is postulated, and yet a clnud is said to consist of vapour. Are we not, in 
our desire to be untechnical, building in these matters without foundations, and was not Huxler's original scheme of "Physiography" a really sound guide to nature-study, even if it made its appeal to children somewhat older than those contemplated in the worls under review?

Prof. Watts, at any rate, agrees with Huxley, and presupposes, in his geological section, a knowledge of the fundamental constituents of the earth. He refers frecly to "silicn," "carbonic acid," "minerals," "mica," and even "hydrated silicate of alumina." After all, is there more in this than is expected of the cliild when he is told to take one quart of milk to James Stewart of Auchencairn and one pint and a half to Mistress Campbell of Drumochter? The milk, the persons, and the farms are realities to him, and are therefore ensy of comprehension. Is there any objection to making him equally well acquainted with the fundamental materials of the land? Prof. Watts gives the teacher the essential conceptions of geology, and leaves him to select what is suited to the comprehension of his class. His style is terse and vivid, and the illustrations selected by him, often from the photographs of Mr. Godfrey Bingley, are in every way worthy of the text. Since the principles of geology are so greatly concerned with the form of the earth's surface, the making of maps and models is included in the course, and the use of the planetable, so attractive to beginners in geography, is explained and illustrated. Several of the technical terms in the chapter on the geological record, "brachiopoda," for instance, are not included in the index to the six volumes of the work; but the author moves on without hesitation-the teacher who undertakes the geological branch of nature-study must be ready to explain such technicalities to his class. Altogether, we cannot conceive a more effective introduction to geology than is here put forward.

To make two small criticisms, in the diagram on p. 2 ro the relations of the upper series of beds seen unnecessarily complicated by a surface-creep towards the valley on one side; and the chapter headed "Igneous Rocks" is mainly concerned with clastic rocks and earth movement. Since the conclusions stated are drawn from observation in our own islands, glaciers and volcanoes are more lightly treated than in many popular works. Prof. WVatts has not gone out of his way to be popular, and has succeeded in being so in the highest of all senses.

Prof. Walther, in his "Vorschule der Geologie," has set much the same goal before himself. In five years his simple little bools has run into four editions, and still forms a treatise that can be easily slipped into the pocket. The author is one of a band of German leaders in education who wish to see geology taught in all secondary (höhere) schools. He here leads on his reader to observe nature out of doors, and in a number of practical exercises shows the varied activities and changes on the surface of the earth. His diagrams are equally simple and convincing, whether of a tree forced to modify the form of its stem through the dorn-creep of a talus (p. II), or of the formation of a granite tor (p. 29) by successive stages of decay. Even Dr. Newbigin would shale her head over Prof. Walther's rain-gauge (p. 42); but his charming directness of style gives one great confidence in his experiments. He permits us chemical formula, and even crystallographic systems; yet his work is quite unlile the text-books familiar in German schools. His little local sketches, such as the section of a swampy area in Fig. 30, are real lessons in geography; indeed, we have shown these pictures to a class in the field in explanation of the broad features of a landscape. IVe may differ with him on small points, such as his treatment of trough-faulting, which surely arises most frequently through the faulting of a fault by one of opposite hade; but he guides us onward from our first observations on a hillside until we can grasp the complexities of a geological map. He expects us to purchase one and use it, and supplies index maps for all the German surveys, with considerable lists of literature to assist our summer holidays. This confidence in the attractiveness of his subject is one of the charms of Prof. IValther's treatise; but re must remember that he appeals to pupils trained by longer working hours than our own, and to the sons and daughters of a people that regards cducation with respect.

Dr. Haas, in "Die vullianischen Gewalten," adds one more to Herre's series of popular scientific monographs. The black-letter type, and occasional sentences in the long blacli-letter style, show that it is intended for general readers beyond the colleges. It is not concerned with personal-observation, but contains, logically stated, the results of a wide range of research. The description of a volcano in time introduces is to earthqualie problems and the constitution of the carth's interior. Though the writers referred to are naturally for the most part German, the author has read widely, and even quotes (p..97) Albert Brun's view that the volcanic cloud consists of salts of ammonia. This leads on to an interesting discussion of how volcanoes might be produced without the presence of water in the original igneous mass, and of Stübel's theory of the formation of calderas by magmatic expansion and subsequent sinking of the central areas. There is much in this "popular" work that will be useful to the teacher of geology: and the illustrations of dust-clouds and lava-flows are refreshingly recent, after the oft-repeated woodcuts to which we have become inured.

Grenville A. J. Cole.

\section{THE MEDIUM OF CELESTIAL SPACE.}

THE phwsicist knows well that the problems with which he has to deal are insignificant, or at best subsidiary, when compared with the great questions so intimately connected, What is matter? and What is xther? The astronomer, though he observes the operations of nature on a vaster scale, deals with problems of a less ultimate character. Thus, when he seeks to investigate the properties of that medium in which the solar system and the stars alike are moving, he is far removed from any metaphysical abstraction, and only seeks the answer to perfectly definite, concrete questions concerning the transparency and dispersive qualities of the medium. But if the questions are concrete, they are by no means simple, and though the last two years have seen a simultaneous attack on the problem on several converging lines, the main result has been to make us realise the immense difficulties which lie in the way of a definite conclusion.

Whether there is a general absorption of light in space, from whatever cause arising, is a point which suggests itself. most obviously. Without attributing any absorptive power to the xther itself, it is casy to see reason for inferring that a loss of light does take place. The streams of meteors which enter our atmosphere have not always been within the sphere of influence of the solar system, but have probably come in incalculable numbers from outer space. Therc is a continual drain on the atmospheres of the sun and planets owing to the loss of the fastest-moving molecules. The empty spaces which have been found to exist in the midst of the densest star clouds, and the curious rifts which interrupt the continuity of certain

NO. 2 I22, VOL. $\left.8_{3}\right]$ 